\title{
Agenesis of the corpus callosum: neonatal ultrasound appearances
}

\section{F SHEEHY SKEFFINGTON}

Department of Paediatrics, Barnsley District General Hospital, Yorkshire

SUMMARY Attention is drawn to the neonata ultrasound appearances in agenesis of the corpus callosum. Although rare, such appearances are highly characteristic, and, if seen, the diagnosis should be easy.

The use of ultrasound head scanning is becoming so common in neonatal units that it is likely that some rare, but once known, easily recognisable, abnormalities will be diagnosed in this way. A case of agenesis of the corpus callosum is described, together with the diagnostic ultrasound appearances.

\section{Case report}

A boy was born after 37 weeks' gestation, weighing $3200 \mathrm{~g}$, after a pregnancy that had been complicated by hydramnios of uncertain cause but was otherwise uneventful. His delivery was by forceps, following a trial of ventouse, and despite reasonable Apgar scores ( 6 at one minute, 8 at five minutes), he looked shocked and was very hypotonic in the 72 hours after birth. He then became irritable and hypertonic, and convulsed at 5 days. After his convulsions had been controlled, his neurological state improved slowly, so that bottle feeding was eventually established by 11 days.

Serial ultrasound scans, through the anterior fontanelle, using an ATL Mark 100 real-time scanner, with three rotating $5 \mathrm{MHz}$ transducers, showed (Fig. 1) wide separation of the lateral ventricles whose anterior horns were narrow, and whose anterior horns and bodies had sharply angled lateral peaks and were concave medially. These were consistent findings in all scans, and real time scanning through the planes posterior to that shown confirmed that the spaces (labelled LV) were in continuity with dilated posterior and inferior horns of lateral ventricles. No structure resembling the corpus callosum could be seen.

In view of multiple minor congenital abnormalities (to be reported separately), chromosome studies were done and showed trisomy 8 , of which agenesis of the corpus callosum is a recognised feature. ${ }^{1}$ A computerised tomography scan (CT) also showed appearances typical of agenesis of the corpus callosum.

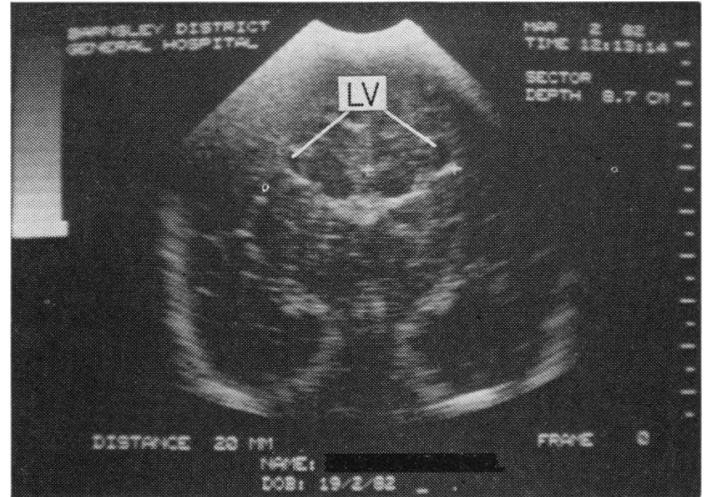

Fig. 1 Mid-coronal section. Anechoic comma-shaped spaces marked $L V$ are the lateral ventricles; real-time scanning through the planes posterior to this shows them in continuity with dilated posterior and inferior horns.

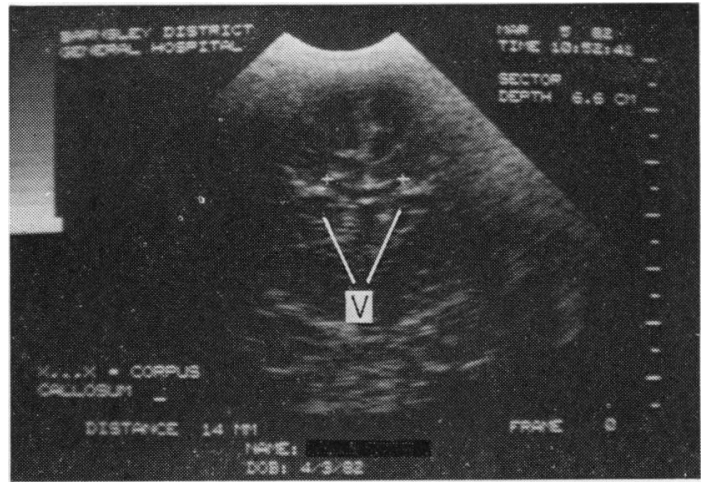

Fig. 2 Mid-coronal scan of a normal 34-week infant. The corpus callosum is the saucer-shaped anechoic space between the signs $+\ldots+$. Lateral ventricles are labelled $V$; the space between them is the cavum septi pellucidi.

\section{Discussion}

Normally (Fig. 2) the corpus callosum is clearly visible on ultrasound scanning of the neonatal head. The anterior horns and bodies of the lateral ventricles are close together, separated anteriorly only by the cavum septi pellucidi. All the features previously 
described for agenesis of the corpus callosum as seen on ventriculography ${ }^{2}$ and CT scanning ${ }^{3}$ can be seen in the present case on ultrasound scanning, with the exception of dilatation of the 3rd ventricle and its interposition between the lateral ventricles. This was not found on the CT scans of the present case either. The degree of dilatation and interposition of the 3rd ventricle is said to be variable ${ }^{3}$ and absence of this finding may mean that the agenesis is incomplete. ${ }^{2}$

Although rare, agenesis of the corpus callosum should be easily recognisable on neonatal ultrasound head scanning.

I thank Dr E M O'Neill, for permission to report this case and Dr I Holland, General Infirmary, Leeds, for the CT scans.
This work was supported by the H F Hawley Trust.

\section{References}

1 Smith D W. Recognizable patterns of human malformation, second edition. Philadelphia: Saunders, 1976: 18-9.

2 Caffey J. Pediatric x-ray diagnosis, fifth edition. Chicago: YB Medical Publishers, 1967: 158-61.

3 Byrd S E, Harwood-Nash D C, Fitz C R. Absence of the corpus callosum: computed tomographic evaluation in infants and children. J Can Assoc Radiol 1978; 29: 108-12.

Correspondence to Dr F Sheehy Skeffington, H F Hawley Perinatal Research Fellow, c/o Ward 10, Barnsley District General Hospital, Gawber Road, Barnsley S75 2EP, Yorkshire.

Received 22 March 1982

\title{
Controlled trial of imipramine in diurnal enuresis
}

\author{
ROY MEADOW AND IAN BERG \\ Department of Paediatrics and Child Health, St James's University Hospital, Leeds
}

SUMMARY Twenty-seven children with diurnal enuresis were studied in a double-blind randomised controlled trial of imipramine. Outcome was not related to such features as age, gender, maximum functional bladder capacity, or evidence of psychiatric disturbance. Although the condition in several children improved, no evidence emerged to suggest that imipramine was superior to placebo in the treatment of the condition.

Day wetting is a troublesome problem which not uncommonly affects children of school age, especially those who wet the bed. The characteristic features of this diurnal form of enuresis have been described elsewhere. ${ }^{12}$ Unfortunately, no effective method of treating wetting, which occurs during the day when the child is up and about, has so far been found. ${ }^{3}$ Imipramine is a drug which relieves bed wetting, at least temporarily. ${ }^{4}$

It was therefore decided to carry out a trial of imipramine in persistent day wetters to see if diurnal enuresis could be lessened.

\section{Procedure}

Children treated at the paediatric outpatient department of a large undergraduate teaching hospital were studied. In each instance a history was taken, a physical examination was carried out, and a midstream specimen of urine was examined. No other special investigations were done routinely. However, since the presence of a urinary tract infection is considered to justify radiological investigation, over half the children had an intravenous urogram and a voiding cystourethrogram. Any urine infection was eradicated before the child was included in the study. During the trial, the urine was checked regularly and kept free from infection. Any child over age 5 years whose daytime wetting was a substantial problem was taken into the trial until it comprised 27 children. Although several also had some bed wetting the main cause of parental concern was the day wetting.

All the mothers completed an Eysenck personality inventory for themselves, and a Rutter A Questionnaire concerned with their children's behaviour. Each was asked to give permission so that the child's school could be visited and the form teacher could complete a Rutter B Questionnaire and a Conners Teachers Questionnaire.

At the first visit to the outpatient department initial clinical assessment included estimation of the maximum functional bladder capacity. Each mother was given a chart to record wetting events during the next 4 weeks before any treatment was started.

On the second visit, it was decided whether the child's wetting was sufficiently troublesome to warrant drug treatment. If so, allocation to the imipramine or the placebo group was made by 